\title{
Repeated Effects of Vigorous Interval Training in Basketball, Running-Biking, and Boxing on the Physical Self-Perceptions of Obese Adolescents
}

\author{
Olivier Rey and Jean-Marc Vallier \\ Université de Toulon, LAMHESS; and Université Côte d'Azur, LAMHESS \\ CAROLINE Nicol \\ Aix Marseille Université; and CNRS, ISM, Institute of Movement Sciences \\ Charles-Symphorien Mercier \\ AJO ${ }^{\circledR}$ Les Oiseaux \\ CHRISTOPHE MAÏANO \\ Université du Québec en Outaouais
}

\begin{abstract}
This study aims to examine the repeated effects of three sessions of vigorous interval training (VIT) in basketball, running-biking, and boxing on the physical self-perceptions (PSP) of obese adolescents participating in a dietary program. A sample of 24 obese adolescents performed the consecutive VIT sessions every week for 5 weeks. PSP were measured immediately after each training session. Analyses of covariance were used to examine changes in PSP. The results showed rapid and constant increases in PSP with significant differences according to sex, time, type of VIT, and an interaction of sex by time by type of VIT, mainly for basketball.
\end{abstract}

\section{INTRODUCTION}

The relationship between obesity and physical activity (including any usual body movement, or planned, structured and repetitive exercises, and any sport participation) is represented by a vicious cycle (Berger, 2004). Indeed, it is now well recognized that insufficient levels of physical activity among youth lead to obesity and that obesity can in turn lead to significantly decreased levels of physical activity (Berger, 2004). This vicious circle is problematic given that physical activity is an effective ingredient for counterbalancing the negative effects of

Received 4 August 2016; accepted 20 May 2017.

Address correspondence to Olivier Rey, LAMHESS - Laboratoire Motricité Humaine, Education, Sport, Santé - EA 6312, USTV, Avenue de l’Université, BP 20132, 83957, Toulon, France. E-mail: olivier.rey@univ-amu.fr 
obesity (Ekkekakis, Vazou, Bixby, \& Georgiadis, 2016). According to Ekkekakis and colleagues (2016), the perceived physical abilities of obese youth may constitute additional barriers to their involvement in regular physical activities. Indeed, obese youth have significantly lower levels of physical self-perceptions (Hau, Sung, Yu, Marsh \& Lau, 2005; Marsh, Hau, Sung, \& Yu, 2007; McCullough, Muldoon, \& Dempster, 2009) than their normal-weight peers. Consequently, as suggested in Harter's (1985) competence motivational theory, if obese youth perceive themselves as less physically competent (e.g., physical condition, sport competence, physical strength, flexibility), they will be less motivated to participate regularly in physical activities.

The enhancement of physical self-perceptions of overweight and obese adolescents through physical activity intervention has thus been emphasized by scholars as a research priority (e.g., Babic et al., 2014). However, very few studies to date have examined the effects of physical activity intervention on physical self-perceptions of overweight or obese youth. Daley, Copeland, Wright, Roalfe, and Wales (2006) examined the effects of an 8-week dietary and aerobic physical activity program (followed by another 6-week program at home) compared with an equal-length exercise placebo intervention (i.e., light body-conditioning/stretching exercises), and with usual care activities among 81 obese adolescents (11-16 years old). The aerobic exercises (e.g., stepping, cycling, rowing, mat dancing, and walking) were performed for $30 \mathrm{~min}$ three times per week targeted at $40 \%$ to $50 \%$ of the reserve heart rate (HR). The physical self-perceptions were measured with the Children and Youth Physical Self-Perception Profile (Fox \& Corbin, 1989; Whitehead, 1995). The results showed that the aerobic exercise group presented significantly higher levels of physical self-worth (at 8 weeks, 14 weeks, and after the follow-up at 28 weeks) and of strength competence (at 8 weeks and 14 weeks) than their counterparts from the usual care group. Additional results showed that the adolescents from the aerobic exercise group tended to present significantly higher levels of global selfworth (at 14 weeks and 28 weeks) than their counterparts from the exercise placebo group. Moreover, the adolescents from the exercise placebo intervention tended to present significantly higher levels of physical self-worth (at 8 weeks) and of global self-worth (at 14 weeks) than their counterparts from the usual care group. Other results also showed that the attractive body adequacy scores decreased significantly at 14 weeks and increased from Week 8 to Week 28 in the exercise therapy and usual care groups. Finally, no significant Group $\times$ Time interaction effect was observed for sports/athletic competence or conditioning competence.

Yu and colleagues (2008) examined the effect of a 6-week program of dietary care alone or dietary care combined with strength training combining aerobic and agility exercises among 82 overweight and obese children ( $8-11$ years old). The program consisted of three sessions per week at $75 \%$ to $100 \%$ of 10 maximal repetitions in the leg and arm muscle groups. A session lasted $75 \mathrm{~min}$, including $10 \mathrm{~min}$ of warm-up, $30 \mathrm{~min}$ of resistance, $10 \mathrm{~min}$ of aerobic exercises (stepper, treadmill, cycling, and aerobic dance at $60 \%-70 \%$ of predicted maximal HR), $10 \mathrm{~min}$ of agility training, and $5 \mathrm{~min}$ of cooldown. The physical self-perceptions were measured with the Physical Self-Description Questionnaire (Marsh, Richards, Johnson, Roche, \& Tremayne, 1994). Their results revealed not only that physical strength significantly improved through both methods but also that dietary care combined with resistance exercises significantly enhanced the children's perceived endurance. However, no significant changes were observed in other physical self-perceptions.

Finally, in the study by Goldfield and colleagues (2015), 304 obese adolescents (1418 years old) were randomized into four groups for 22 weeks of aerobic training, resistance training, aerobic-resistance training, or control (no exercise). The participants were involved in four sessions per week lasting between 20 and 45 min: (a) 65\%-85\% of maximal HR using a 
cycle-ergometer or treadmill for the aerobic training group and (b) from two sets of 15 moderate repetitions to three sets of eight maximal repetitions for the resistance training group. The physical self-perceptions were measured with the Physical Self Perception Profile for Children (Fox \& Corbin, 1989; Whitehead, 1995). The results from this study show a significant effect of time (between baseline and 6 months) for all groups on sport competence, physical condition, body satisfaction, physical strength, physical self-worth, and global self-esteem (except for the control group). Additional results showed significant Group $\times$ Time interaction effects on physical condition (greater increase in the aerobic-resistance group compared with the control group), physical strength (greater increase in the resistance and aerobic-resistance groups compared with the control group), and global self-esteem (greater increase in the resistance group compared with the control group). Finally, no significant Group $\times$ Time interaction effects were observed for sport competence, body satisfaction, or physical self-worth.

The aforementioned studies have three important limitations. First, most of the studies focused on aerobic exercises combined or not with resistance ones. The frequent use of aerobic exercises is surprising because this type of exercise is associated with a long exercise period, is often rated by overweight or obese youth as uncomfortable and unpleasant (Bartlett et al., 2011; Ekkekakis \& Petruzzelo, 1999), and may explain the high attrition rates in exercise interventions among this population (Epstein \& Goldfield, 1999). Yet, vigorous and highintensity training was recently highlighted (e.g., Alahmadi, 2014; Logan, Harris, Duncan, \& Schofield, 2014) as having significant effects on physiological parameters (e.g., Gibala, Little, MacDonald, \& Hawley, 2012) and physical fitness (e.g., Costigan, Eather, Plotnikoff, Taaffe, \& Lubans, 2015). Therefore, it can be deduced that shorter and more intensive workouts are likely to be associated with better effects on physical self-perceptions. Considering the specificity of obesity, the submaximal but vigorous intermittent training (VIT) can be recommended as a good alternative to continuous aerobic exercises or to supramaximal ones for attaining physiological and psychological benefits (Babic et al., 2014; Farah, Ritti-Dias, Balagopal, Hill, \& Prado, 2014; Garcia-Hermoso et al., 2016; Jakicic, Marcus, Gallagher, Napolitano, \& Lang, 2003).

Second, none of these studies measured the repeated effects of physical activity interventions on physical self-perceptions. Consequently, we have little information on reactivity and the time needed to induce changes in physical self-perceptions. This question is essential to understanding how physical activity interventions can improve general and specific perceived physical abilities of obese adolescents.

Third, none of the previous studies examined whether the repeated effects of physical activity interventions were greater among girls than boys. However, it is well recognized in the literature that overweight-obese girls have significantly lower physical self-perceptions than overweight-obese boys (e.g., Hau et al., 2005; Marsh, Hau, Sung, \& Yu, 2007; Sung, Yu, So, Lam, \& Hau, 2005). Therefore, it is unknown how girls' and boys' physical self-perceptions differ according to their physical activity experience.

The main objective of the present study was to examine the repeated effects of three sessions of VIT in basketball, running-biking, and boxing on the physical self-perceptions (PSP) of obese adolescents involved in a dietary program. In the present study, VIT is defined as a modality of interval efforts interrupted by rest periods with exercise intensity above the ventilatory threshold (Tan, Yang, \& Wang, 2010) and at a high percentage of maximal HR solicitations. More specifically, it corresponds to an intensity of at least $80 \%$ of the theoretical maximal $\mathrm{HR}$ and an energy expenditure of at least $6 \mathrm{Kcal} / \mathrm{min}$. The basketball, running-biking, and boxing VIT sessions differed in terms of work and rest (i.e., in the net duration of the successive bouts of effort and passive recovery), and their practice order was counterbalanced 
between the participants. During each session, the target exercise intensity $(80 \%$ theoretical maximal HR) was systematically controlled. The global pre- versus post-test effects of this 5week VIT program on body composition, physical self-perceptions, physical fitness, and physiological responses have been published by Rey, Vallier, Nicol, Mercier, and Maïano (2017).

More specifically, the present study pursued three objectives. The first was to examine the repeated effects of VIT sessions on physical self-perceptions. It was hypothesized that physical self-perceptions would improve significantly with time.

The second was to compare the repeated effects of basketball, running-biking, and boxing VIT sessions on the physical self-perceptions of obese adolescents. Their physical selfperceptions were expected to improve significantly with time for all sport practices, but the greatest changes were expected to occur in boxing. Indeed, as suggested by Jung, Bourne, and Little (2014), it is probable that the higher number of recovery periods in boxing could decrease time commitment and monotony and thus elicits more positive emotional responses, such as pride and accomplishment, than in running-biking and basketball.

The third objective was to examine whether the repeated effects of the basketball, runningbiking, and boxing VIT sessions differed according to the participants' sex. Because girls have lower PSP than boys (Maïano, Ninot, \& Bilard, 2004; Marsh, 1998), it was hypothesized that the effects of the VIT sessions on physical self-perceptions would be more pronounced for girls than for boys.

\section{METHODS}

\section{Participants}

A sample of 30 obese adolescents schooled in a southern French pediatric rehabilitation center participated in this crossover study from January to March 2011. Six participants were excluded from the analysis because they failed to complete the program due to several absences (because of appointments with the medical staff or minor leisure time injuries or illness). The present study focuses on the 24 remaining participants (14 girls, 10 boys, Tanner's Stage III-IV; $M=14.6$ years old, $S D=0.7$ ) who performed all the training sessions and completed all the measures. These participants were considered obese based on their body mass index (BMI; $\left.M=32.64 \mathrm{Kg} / \mathrm{m}^{2}, S D=4.88\right)$ and percentage of body fat $(M=36.75 \%$, $S D=7.04)$. The obesity BMI category was determined based on their sex- and age-specific cutoff scores provided by the International Obesity Task Force (Cole, Bellizzi, Flegal, \& Dietz, 2000). None of the participants had any metabolic, cardiac, or orthopedic disorder, nor were they receiving any medical treatment that might have interfered with the study.

The protocol was constructed in accordance with the Declaration of Helsinki and met France's ethical requirements for human research. Permission to conduct the study was first obtained from the administration and medical staff of the pediatric rehabilitation center. An information letter was then sent to the adolescents' parent or legal representative, and only adolescents who returned the signed consent forms participated. The entire protocol was conducted by the first author, Olivier Rey, under the supervision of the medical staff of the pediatric rehabilitation center.

\section{Sessions of Vigorous Interval Training}

Each participant performed consecutive VIT sessions in basketball, running-biking, and boxing every week for 5 weeks ( 15 sessions total) during a $1 \mathrm{hr}$ session, with 45 min of effective physical activity. These VIT sessions were performed at a physiological intensity of at 
least $80 \%$ of the theoretical maximal HR and above $6 \mathrm{Kcal} / \mathrm{min}$ (about four Metabolic Equivalents of Task for our population) as defined by the American College of Sports Medicine (Donnelly et al., 2009). The sample included both female and male adolescents. The sessions were managed by the investigator, a physical educator, and two assistants under the medical staff's supervision. The sessions took place on the same days (Mondays, Wednesdays, and Fridays) and at the same time (between 8:30 a.m. and noon), during a follow-up where the participants followed the same dietary program (an average daily energy intake of $2000 \mathrm{Kcal}$ for girls and $2200 \mathrm{Kcal}$ for boys). Each portion of food was measured and served by the staff of the pediatric rehabilitation center.

Basketball, running-biking, and boxing were retained because (a) they were the sport activities conventionally used in the management of obese young people in the pediatric center where the study was carried out, (b) they involved intermittent efforts, and (c) they differed in nature (team, individual, and combat sport) and thus helped to stimulate the participants' immediate motivation and to avoid boredom and disengagement. Their order of practice within the VIT sessions was counterbalanced, and the sessions were $48 \mathrm{hr}$ apart.

The Basketball VIT sessions consisted of three 10-min periods of three-on-three basketball games on a half court with intermediate rest periods of 3 min (i.e., a 36 min exercise with work-rest ratio of 10:3, net workout duration $=30 \mathrm{~min}$ ).

The Running-Biking VIT sessions consisted of two exercises randomly performed for $3 \mathrm{~min}$ with 3 min passive resting intervals repeated two times with a 3-min intermediate passive rest period (i.e., a $21 \mathrm{~min}$ exercise with work-rest ratio of 1:1; net workout duration $=12 \mathrm{~min}$ ). The biking exercise was performed at a free cadence for a maximal theoretical distance (given by the counter) against a mechanical resistance of 4 out of 10 on a cycle ergometer (Kettler "Golf M" model, Ense, Germany). The running exercise consisted in covering a maximal distance around a $150 \mathrm{~m}$ track. The intensity of the exercise was "all-out," as it was performed to realize the 3 min maximal distance. During the program, a distance challenge had to be implemented to motivate the participants to truly make an all-out effort.

The Boxing VIT sessions consisted of three 8 min sequences of repeating $10 \mathrm{~s}$ of noncontact boxing followed by $20 \mathrm{~s}$ of passive rest (i.e., a 32 min exercise with work-rest ratio of $1: 2$, net workout duration $=8 \mathrm{~min}$ ). The time was indicated by a music sequence consisting of two songs to impulse work and rest. Each of the three sequences was separated by a 4-min passive rest period. The boxing exercise intensity was "all-out," as it was performed at maximal intensity and frequency by kicking and boxing with gloves against a punching bag.

Although all the VIT sessions lasted $45 \mathrm{~min}$, they differed in the net training duration, that is, the real time spent working intensively. During rest periods, the participants remained standing or walked around slowly. During each session, the participants systematically carried the HR monitor with their individual parameters, and their target exercise intensity was controlled in vivo (Howley, 2001). Adolescents who did not reach target HR were asked (by the experimenter) to increase their rhythm or engagement. Nevertheless, the adolescents received no special motivational encouragement.

\section{Measures}

\section{Body composition}

All anthropometric measures were taken before and after the VIT program by the medical staff. The participants' standing height (with a precision of $1 \mathrm{~cm}$ ) was measured using a Harpenden stadiometer. Their BMI was calculated individually based on their measured height and weight $\left(B M I=\right.$ weight $[\mathrm{Kg}] /$ height $\left.^{2}[\mathrm{~m}]\right)$. Skinfold thickness was measured at four 
sites (bicipital, tricipital, subscapularis, and suprailiac) with a Harpenden clamp. This measure was used to estimate the body fat (BF) percentage, using Siri's (1961) equation, BF percentage $=100 \times(4.95 / \mathrm{BD}-4.50)$, and the body density $(\mathrm{BD})$ was calculated using Durnin and Womersley's (1974) equation, BD $=1.1369-\left(0.0598^{*}\right.$ LOG10 ( $\sum 4$ Skinfolds $\left.)\right)$, for adolescent boys and girls.

\section{HR measurement and target value}

HR was individually recorded throughout every session using an HR monitor (Polar Team Pro, Polar Electro Oy, Kempele, Finland). Peak heart rate value $\left(\mathrm{HR}_{\text {peak }}\right)$ and mean $\left(\mathrm{HR}_{\text {mean }}\right)$ were continuously recorded throughout the VIT period as well as during the standardized warm-up and the final passive rest periods. The HR target value was established with the percentage of the maximum $\mathrm{HR}\left(\mathrm{HR}_{\max }\right)$ estimation using the $(208-[0.7 \times$ age $])$ formula provided by Tanaka, Monahan, and Seals (2001). To be considered a vigorous workout, each VIT session had to aim at inducing an $\mathrm{HR}_{\text {peak }}$ of at least $80 \%$ of the participants' theoretical $\mathrm{HR}_{\max }$ (157 beats per minute on average for 14.6-year-old adolescents). For analysis purposes, $\mathrm{HR}_{\text {peak }}$ was the mean of the four highest $\mathrm{HR}$ values. The average $\mathrm{HR}\left(\mathrm{HR}_{\text {mean }}\right)$ per VIT session was also calculated for its $45 \mathrm{~min}$ duration, including the standardized warm-up, the VIT exercise, and the cooldown periods.

\section{Assessment of physical activity}

A validated (Powell \& Rowlands, 2004; Rowlands, Ingledew, Powell, \& Eston, 2004) triaxial accelerometer (RT3, Stayhealthy Inc., Monrovia, CA) was used to assess the estimated intensity and energy expenditure of the participants' physical activity (Westerterp, 1999) from the start to the end of each 45-min exercise session. The accelerometer was carried by the belt on the right hip. To assess each exercise condition, the energy expenditure expressed in Kcal was estimated with the accelerometers and converted to the rate of energy consumption in $\mathrm{Kcal} / \mathrm{min}$. Because the objective was to couple measures of HR and energy expenditure to ensure that the efforts were in the target area, the hypothetical underestimated values in cycling (Tarp, Andersen, \& Østergaard, 2015) or boxing were considered negligible.

\section{Physical self-perceptions}

PSP were measured with the very short form of the validated Physical Self-Inventory (PSIVS; Maïano et al., 2008; Morin \& Maïano, 2011). This questionnaire comprises 12 items measuring six physical self-dimensions (two items per dimension): global self-worth (GSW; e.g., "I have a good opinion of myself"), physical self-worth (PSW; e.g., "I'm happy with what I can do physically"), physical strength (PS; e.g., "I would be good at exercises that require strength"), physical condition (PC; e.g., "I would be good at physical stamina exercises"), physical attractiveness (PA; "I have a nice body to look at"), and sport competence (SC; e.g., "I do well in sports"). Participants rate each sentence using a 6-point Likert scale ranging from 1 (not at all) to 6 (entirely). The PSI-VS was introduced and explained to the participants before they began filling it out. It was completed immediately after each training session, and the participants were instructed to respond to the items based on their latest practice session. To avoid a learning effect, three versions of the PSI-VS in which the order of the items were counterbalanced were used. The mean of Cronbach's alpha values across the 15 posttests repeated measures of the PSI-VS were acceptable: GSW $\left(M \alpha_{\text {post-VIT }}=.74\right)$, PSW $\left(M \alpha_{\text {post-VIT }}=.77\right), \mathrm{PS}\left(M \alpha_{\text {post-VIT }}=.60\right), \mathrm{PC}\left(M \alpha_{\text {post-VIT }}=.84\right), \mathrm{PA}\left(M \alpha_{\text {post-VIT }}=.79\right), \mathrm{SC}$ $\left(M \alpha_{\text {post-VIT }}=.66\right)$, considering the very low number of items per scale. 


\section{Statistical Analyses}

All analyses were performed using Statistica 12.0 (Statsoft Inc., Tulsa, OK). An independent-samples Student $t$ test was used to examine the sex-based differences on descriptive and anthropometric characteristics. In addition, an analysis of variance was used to examine the differences between $\mathrm{HR}_{\text {peak }}, \mathrm{HR}_{\text {mean }}$, and $\mathrm{Kcal} / \mathrm{min}$ across every type of VIT. Finally, a three-way analysis of covariance (controlling for delta-weight scores between pre- and postintervention) was used to examine the effects of the type of VIT (basketball, running-biking, and boxing), time (Session 1 [S1] to Session 5 [S5]), sex, and their interaction (Type of VIT $\times$ Sex, Type of VIT $\times$ Time, Time $\times$ Sex, Type of VIT $\times$ Sex $\times$ Time $)$ on physical selfperceptions. In case of significance $(p<.05)$, a Student Newman-Keuls post hoc test was used. The effect sizes of significant post hoc effects were estimated using Cohen's (1988) $d$ (small effect size $=0.2 \leq d<0.5$, medium effect size $=0.5 \leq d<0.8$, large effect size $=d$ $\geq 0.8$ ).

\section{RESULTS}

\section{Sex-Based Difference in Descriptive and Anthropometric Characteristics}

No sex-based differences were observed regarding the participants' age $(p=.30)$, body weight $(p=.34)$, BMI $(p=.60)$, or body fat percentage $(p=.23)$. However, as illustrated in Table 1 , the boys were taller than the girls $(p<.005)$. After 5 weeks (Table 1$)$, the body fat percentage was reduced by $7.5 \%, F(1,22)=44.76, p<.001, d=0.42$, and the mean weight, by $3.6 \%(-3.03 \mathrm{~kg}, S D=3.02), F(1,22)=44.23, p<.001, d=0.20$. The BMI mean was also significantly reduced, $F(1,22)=52.56, p<.001, d=0.27$. The girls had lost $3.01 \mathrm{~kg}$ $(S D=2.05)$ and the boys $3.49 \mathrm{~kg}(S D=2.96)$. As previously mentioned, this information was used as a covariate in the subsequent analyses.

\section{Characteristics of the Three Types of VIT}

Table 2 presents the group-averaged heart rate and the energy expenditure values for each VIT session and for the five sessions by VIT type. Based on the $\mathrm{HR}_{\text {peak }}$ values and energy

Table 1

Participants' Demographic and Anthropometric Characteristics

\begin{tabular}{|c|c|c|c|c|c|c|}
\hline & \multicolumn{2}{|c|}{ Total $^{\mathrm{a}}$} & \multicolumn{2}{|c|}{ Boys ${ }^{b}$} & \multicolumn{2}{|c|}{ Girls $^{c}$} \\
\hline & Pre-VIT & Post-VIT & Pre-VIT & Post-VIT & Pre-VIT & Post-VIT \\
\hline Age (years) & \multicolumn{2}{|c|}{$14.6(0.7)$} & \multicolumn{2}{|c|}{$14.4(0.7)$} & \multicolumn{2}{|c|}{$14.7(0.7)$} \\
\hline Height (cm) & $165.8(7.7)$ & $166.3(7.8)$ & $171.1(7.6)^{*}$ & $171.8(7.4)$ & $161.9(5.3)^{*}$ & $162.4(5.5)$ \\
\hline Weight (kg) & 89.7 (16.5) & $86.5(15.4)^{\dagger}$ & $93.6(22.9)$ & $90.2(21.1)$ & $86.9(10.1)$ & $83.9(9.9)$ \\
\hline BMI $\left(\mathrm{kg} / \mathrm{m}^{2}\right)$ & $32.6(4.8)$ & $31.3(4.6)^{\dagger}$ & $31.9(6.0)$ & $30.3(5.6)$ & $33.2(4.0)$ & $32.0(4.3)$ \\
\hline Body fat (\%) & $36.8(7.0)$ & $34.0(6.0)^{\dagger}$ & 34.7 (9.7) & $30.9(7.4)$ & $38.4(4.2)$ & $36.2(3.7)$ \\
\hline
\end{tabular}

Note. Values are mean (standard deviation). VIT = vigorous interval training; BMI = body mass index.

${ }^{\mathrm{a}} N=24$.

$\mathrm{b}_{n}=10$.

${ }^{\mathrm{c}} n=14$.

† Significant difference from preintervention values at $p<.001 .{ }^{*}$ Main effect of sex, significant difference at $p<$ .001 . 
Table 2

Mean of Heart Rate, Energy Expenditure, and Intensity for Each Session and Types of VIT

\begin{tabular}{|c|c|c|c|c|c|c|c|}
\hline \multirow[b]{3}{*}{ Measures } & \multirow[b]{3}{*}{ Sessions } & \multicolumn{6}{|c|}{ Type of VIT } \\
\hline & & \multicolumn{2}{|c|}{ Basketball } & \multicolumn{2}{|c|}{ Running-biking } & \multicolumn{2}{|c|}{ Boxing } \\
\hline & & M & (SD) & M & (SD) & $\mathbf{M}$ & (SD) \\
\hline \multirow[t]{6}{*}{ HRpeak (bpm) } & 1 & 187 & (10) & 183 & (11) & 164 & (12) \\
\hline & 2 & 189 & (21) & 188 & (12) & 167 & (14) \\
\hline & 3 & 182 & (9) & 182 & (15) & 157 & (16) \\
\hline & 4 & 185 & (10) & 176 & (12) & 167 & (15) \\
\hline & 5 & 194 & (11) & 178 & (15) & 161 & (19) \\
\hline & $M$ & 187 & $(14)_{a, b}$ & 181 & $(14)_{\mathrm{a}, \mathrm{c}}$ & 163 & $(16)_{b, c}$ \\
\hline \multirow[t]{6}{*}{ HRmean (bpm) } & 1 & 127 & (9) & 135 & (13) & 119 & (9) \\
\hline & 2 & 128 & (13) & 141 & (17) & 123 & $(8)$ \\
\hline & 3 & 120 & (10) & 133 & (15) & 114 & (12) \\
\hline & 4 & 129 & (12) & 131 & (13) & 124 & (12) \\
\hline & 5 & 130 & (10) & 128 & (13) & 114 & (11) \\
\hline & $M$ & 127 & $(11)_{a, b}$ & 134 & $(16)_{\mathrm{a}, \mathrm{c}}$ & 119 & $(11)_{b, c}$ \\
\hline \multirow[t]{6}{*}{ Total energy expenditure (Kcal) } & 1 & 420 & $(79)$ & 430 & $(83)$ & 421 & $(82)$ \\
\hline & 2 & 402 & (72) & 426 & $(101)$ & 425 & (87) \\
\hline & 3 & 434 & $(85)$ & 436 & $(85)$ & 413 & (83) \\
\hline & 4 & 422 & (87) & 430 & $(80)$ & 433 & (86) \\
\hline & 5 & 417 & (86) & 407 & (79) & 408 & $(80)$ \\
\hline & $M$ & 419 & $(81)$ & 426 & $(85)$ & 420 & $(83)$ \\
\hline \multirow[t]{6}{*}{ Exercise intensity (Kcal/min) } & 1 & 9.3 & $(1.8)$ & 9.6 & $(1.8)$ & 9.4 & $(1.8)$ \\
\hline & 2 & 8.9 & $(1.6)$ & 9.5 & $(2.2)$ & 9.4 & (1.9) \\
\hline & 3 & 9.7 & (1.9) & 9.7 & (1.9) & 9.2 & (1.8) \\
\hline & 4 & 9.4 & (1.9) & 9.6 & (1.8) & 10.6 & (1.9) \\
\hline & 5 & 9.3 & (1.9) & 9.1 & (1.8) & 9.1 & (1.8) \\
\hline & $M$ & 9.3 & (1.8) & 9.5 & (1.9) & 9.3 & (1.8) \\
\hline
\end{tabular}

Note. Subscripts refer to the values that differed significantly from one another $(p<.05)$. VIT $=$ vigorous interval training; $\mathrm{HR}=$ heart rate; $\mathrm{bpm}=$ beats per minute.

expenditure rate, each of the VIT sessions was vigorous, as they were performed at a physiological intensity of at least $80 \%$ of the theoretical maximal HR and over $6 \mathrm{Kcal} / \mathrm{min}$. The analysis of variance revealed significant differences across VIT types in $\mathrm{HR}_{\text {peak }}$ values but no differences in the energy expenditure total and rate. Indeed, the basketball VIT provided higher $\mathrm{HR}_{\text {peak }}$ mean values than the running-biking VIT ( $\left.p=.046, d=0.47\right)$, and the runningbiking VIT elicited higher $\mathrm{HR}_{\text {peak }}$ mean values than the boxing VIT $(p<.001, d=1.21)$. These mean $\mathrm{HR}_{\text {peak }}$ values corresponded to $94.5 \%, 91.5 \%$, and $83.4 \%$, respectively, of the theoretical $\mathrm{HR}_{\max }$ values. Significant differences were also found among the VIT types of session in terms of $\mathrm{HR}_{\text {mean }}$ values including the warm-up, recoveries and workout periods, and cooldown, over the 45 min (Table 2).

\section{Changes in Physical Self-Perceptions}

At baseline, the PSP scores were significantly higher for the boys, $F(6,17)=3.13, p=$ $.030, d=0.61$, than for the girls: respectively, GSW $=3.6, S D=1.4$ vs. $2.6, S D=0.9$; $\mathrm{PSW}=3.4, S D=1.2$ vs. $2.7, S D=0.7 ; \mathrm{PS}=3.1, S D=1.1$ vs. $2.8, S D=1.1 ; \mathrm{PC}=2.3, S D$ $=1.4$ vs. $1.4, S D=0.5 ; \mathrm{PA}=3.5, S D=1.3$ vs. $2.7, S D=0.6$; and $\mathrm{SC}=2.9, S D=1.9$ vs. $2.5, S D=0.7)$. 
The mean and standard deviation of all the PSI-VS subscales across the types of VIT, time, and sex are presented in Table 3. As shown in Table 4, no significant effects were found for the covariate (delta of weight loss), the VIT or the VIT $\times$ Sex and VIT $\times$ Sex $\times$ Time interaction effects. However, significant main effects of time (Figure 1A) and sex and VIT $\times$ Time (Figure 1B) and Sex $\times$ Time interaction effects were observed (Table 4). These effects are described next.

\section{Global self-worth}

A significant VIT $\times$ Time effect was found (Table 4), and post hoc analyses showed a significant decrease between S1 and S3 $(p=.045, d=-0.91)$ for the boxing VIT. In addition, significant main time and sex effects were observed (Table 4$)$. Post hoc analyses revealed that boys reported higher scores than girls $(p<.001, d=0.72)$ but failed to find any significant difference for time.

\section{Physical self-worth}

No interaction effects were observed (Table 4). However, significant main effects of time or sex were found (Table 4$)$. They show that boys reported higher scores than girls $(p=.008$, $d=0.56)$ and that scores increased between S1 and S5 $(p=.025, d=0.34)$ and between S2 and S5 $(p=.009, d=0.37)$.

\section{Physical strength}

A significant VIT $\times$ Time effect was observed (Table 4). Post hoc analyses showed that scores significantly increased between S1 and S3 $(p=.003, d=-0.33)$ for the boxing VIT. In addition, the significant Sex $\times$ Time effect indicated that boys' PS scores decreased between $\mathrm{S} 1$ and S2 $(p=.004, d=-0.47)$ and increased between S2 and S3 $(p<.001, d=1.09), \mathrm{S} 2$ and S4 $(p<.001, d=0.74)$, and S2 and S5 $(p<.001, d=0.97)$. Finally, a significant Time $\times$ Sex effect was found (Table 4$)$. The findings show that boys reported higher scores than girls $(p<.001, d=0.73)$ and that the scores increased between S2 and S3 $(p=.005, d=0.46)$, $\mathrm{S} 2$ and $\mathrm{S} 4(p=.017, d=0.37)$, and S2 and S5 $(p=.032, d=0.31)$.

\section{Physical condition}

A significant VIT $\times$ time effect indicated that scores (a) increased significantly between $\mathrm{S} 1$ and S2 $(p<.001, d=1.07), \mathrm{S} 1$ and S3 $(p=.006, d=0.68), \mathrm{S} 1$ and S4 $(p=.002, d=$ $0.76)$, and S1 and S5 ( $p<.001, d=0.90)$ for the basketball VIT and (b) decreased between $\mathrm{S} 1$ and S2 $(p=.029, d=-0.40)$ but increased between S2 and S3 $(p=.021, d=0.59)$, S2 and S4 $(p=.019, d=0.48)$, and S2 and S5 $(p<.001, d=0.77)$ for the running-biking VIT. In addition, significant main effects of sex and time were observed (Table 4). Post hoc analyses revealed that boys reported higher scores than girls $(p=.003, d=0.59)$ and that scores increased between S1 and S2 $(p=.038, d=0.22)$, S1 and S4 $(p=.023, d=0.30)$, and $\mathrm{S} 1$ and $\mathrm{S} 5(p<.001, d=0.43)$.

\section{Physical attractiveness}

A significant VIT $\times$ Time effect was observed (Table 4), but the post hoc analyses failed to find any significant difference. The significant main effect of sex revealed that boys reported higher scores than girls $(p<.001, d=0.68)$.

\section{Sport competence}

The significant VIT $\times$ Time effect revealed that scores (a) increased between S1 and S5 ( $p$ $=.004, d=0.74)$ for the basketball VIT, (b) decreased between S1 and S2 ( $p=.038, d=$ 
Table 3

Measures of Physical Self-Perceptions According to the Types of VIT Sessions, Time, and Sex

\begin{tabular}{|c|c|c|c|c|c|c|c|c|c|c|}
\hline \multirow[b]{2}{*}{ Scales } & \multirow[b]{2}{*}{ Sessions } & \multicolumn{3}{|c|}{ Basketball } & \multicolumn{3}{|c|}{ Running-biking } & \multicolumn{3}{|c|}{ Boxing } \\
\hline & & $\begin{array}{c}\text { Total M } \\
\text { (SD) }\end{array}$ & $\begin{array}{c}\text { Boys M } \\
\text { (SD) }\end{array}$ & $\begin{array}{c}\text { Girls M } \\
\text { (SD) }\end{array}$ & $\begin{array}{c}\text { Total M } \\
\text { (SD) }\end{array}$ & $\begin{array}{c}\text { Boys M } \\
\text { (SD) }\end{array}$ & $\begin{array}{c}\text { Girls M } \\
\text { (SD) }\end{array}$ & $\begin{array}{c}\text { Total M } \\
\text { (SD) }\end{array}$ & $\begin{array}{c}\text { Boys M } \\
\text { (SD) }\end{array}$ & $\begin{array}{c}\text { Girls M } \\
\text { (SD) }\end{array}$ \\
\hline \multirow[t]{6}{*}{ Global Self-Worth } & 1 & $3.0(1.1)$ & $3.6(1.4)$ & $2.6(0.9)$ & $2.4(1.1)$ & $3.0(1.4)$ & $2.1(0.7)$ & $3.2(0.8)$ & $3.3(0.8)$ & $3.1(0.9)$ \\
\hline & 2 & $2.4(0.8)$ & $3.0(0.7)$ & $2.1(0.6)$ & $2.7(1.2)$ & $3.2(1.2)$ & $2.4(0.1)$ & $2.7(0.8)$ & $3.0(0.8)$ & $2.5(0.9)$ \\
\hline & 3 & $2.6(0.8)$ & $2.7(0.8)$ & $2.5(0.8)$ & $2.6(1.1)$ & $3.0(0.9)$ & $2.4(1.1)$ & $2.5(0.7)$ & $2.5(0.5)$ & $2.4(0.9)$ \\
\hline & 4 & $2.9(0.9)$ & $2.9(0.8)$ & $2.4(0.9)$ & $3.1(1.1)$ & $3.7(1.2)$ & $2.8(0.9)$ & $2.9(1.2)$ & $3.7(0.9)$ & $2.4(1.1)$ \\
\hline & 5 & $2.8(1.4)$ & $3.5(0.7)$ & $2.4(1.1)$ & $2.7(1.2)$ & $3.1(1.2)$ & $2.5(1.1)$ & $2.9(1.2)$ & $3.4(0.9)$ & $2.6(1.3)$ \\
\hline & $M$ & $2.7(1.0)$ & $3.1(0.9)$ & $2.4(0.9)$ & $2.7(1.1)$ & $3.2(1.2)$ & $2.4(1.0)$ & $2.8(1.0)$ & $3.2(0.8)$ & $2.6(1.0)$ \\
\hline \multirow[t]{6}{*}{ Physical Self-Worth } & 1 & $3.0(1.0)$ & $3.4(1.2)$ & $2.7(0.7)$ & $2.9(1.2)$ & $3.6(1.3)$ & $2.5(0.9)$ & $3.3(1.2)$ & $3.7(1.2)$ & $3.0(1.1)$ \\
\hline & 2 & $3.0(1.0)$ & $3.3(1.0)$ & $2.8(1.1)$ & $3.1(0.9)$ & $3.7(0.8)$ & $2.8(0.8)$ & $3.2(1.0)$ & $3.5(1.1)$ & $3.0(1.0)$ \\
\hline & 3 & $3.1(1.0)$ & $3.4(1.3)$ & $2.9(0.8)$ & $2.9(1.1)$ & $3.2(0.9)$ & $2.8(1.1)$ & $3.6(0.9)$ & $3.7(0.8)$ & $3.5(1.0)$ \\
\hline & 4 & $3.2(0.8)$ & $3.2(0.8)$ & $3.1(0.9)$ & $3.3(1.0)$ & $3.9(0.7)$ & $2.9(0.9)$ & $3.3(1.0)$ & $3.3(0.9)$ & $3.2(1.0)$ \\
\hline & 5 & $3.4(1.0)$ & $3.7(1.1)$ & $3.2(1.0)$ & $3.4(1.0)$ & $3.8(0.9)$ & $3.2(1.0)$ & $3.4(1.0)$ & $3.6(1.0)$ & $3.2(1.0)$ \\
\hline & $M$ & $3.1(1.0)$ & $3.4(1.0)$ & $2.9(0.9)$ & $3.1(1.0)$ & $3.7(0.9)$ & $2.8(1.0)$ & $3.3(1.0)$ & $3.6(1.0)$ & $3.2(1.0)$ \\
\hline \multirow[t]{6}{*}{ Physical Strength } & 1 & $2.9(1.1)$ & $3.1(1.2)$ & $2.8(1.1)$ & $2.8(1.3)$ & $3.8(1.3)$ & $2.2(0.9)$ & $2.4(1.0)$ & $2.8(1.2)$ & $2.2(0.8)$ \\
\hline & 2 & $2.4(0.8)$ & $2.4(0.9)$ & $2.4(0.8)$ & $2.8(1.0)$ & $2.9(0.9)$ & $2.7(1.1)$ & $2.6(0.8)$ & $2.8(0.7)$ & $2.5(0.9)$ \\
\hline & 3 & $3.0(0.9)$ & $3.7(0.7)$ & $2.6(0.8)$ & $2.8(1.0)$ & $3.3(0.8)$ & $2.5(1.1)$ & $3.3(0.8)$ & $3.6(0.5)$ & $3.1(0.8)$ \\
\hline & 4 & $2.9(1.0)$ & $3.4(0.9)$ & $2.6(1.0)$ & $3.3(1.1)$ & $3.7(1.2)$ & $3.0(1.0)$ & $2.7(0.9)$ & $3.0(0.8)$ & $2.4(1.0)$ \\
\hline & 5 & $2.7(1.0)$ & $3.2(0.8)$ & $2.4(1.0)$ & $3.0(1.2)$ & $3.8(1.1)$ & $2.5(0.9)$ & $3.0(1.0)$ & $3.6(0.8)$ & $2.6(1.0)$ \\
\hline & $M$ & $2.8(1.0)$ & $3.2(1.0)$ & $2.6(0.9)$ & $2.9(1.1)$ & $3.5(1.1)$ & $2.6(1.0)$ & $2.8(0.9)$ & $3.2(0.9)$ & $2.5(0.9)$ \\
\hline \multirow[t]{6}{*}{ Physical Condition } & 1 & $1.7(1.0)$ & $2.3(1.4)$ & $1.4(0.5)$ & $2.2(1.2)$ & $3.0(1.5)$ & $1.7(0.7)$ & $2.5(0.9)$ & $2.7(1.1)$ & $2.4(0.8)$ \\
\hline & 2 & $2.8(0.9)$ & $3.0(0.8)$ & $2.7(1.0)$ & $1.8(0.9)$ & $2.2(1.0)$ & $1.5(0.8)$ & $2.6(1.0)$ & $3.0(1.1)$ & $2.4(1.0)$ \\
\hline & 3 & $2.4(1.0)$ & $3.9(1.1)$ & $2.1(0.9)$ & $2.3(1.0)$ & $2.6(1.0)$ & $2.2(1.0)$ & $2.5(1.0)$ & $2.6(1.1)$ & $2.4(1.0)$ \\
\hline & 4 & $2.5(1.0)$ & $2.7(1.1)$ & $2.4(1.0)$ & $2.3(1.3)$ & $3.0(1.2)$ & $1.9(1.2)$ & $2.6(0.9)$ & $2.9(0.6)$ & $2.5(1.0)$ \\
\hline & 5 & $2.6(0.9)$ & $2.8(0.9)$ & $2.5(1.0)$ & $2.6(1.3)$ & $3.3(1.4)$ & $2.2(1.2)$ & $2.6(1.2)$ & $3.1(1.2)$ & $2.4(1.1)$ \\
\hline & $M$ & $2.4(1.0)$ & $2.7(1.1)$ & $2.2(1.0)$ & $2.2(1.2)$ & $2.8(1.2)$ & $1.9(1.0)$ & $2.6(1.0)$ & $2.8(1.0)$ & $2.4(1.0)$ \\
\hline
\end{tabular}




\begin{tabular}{lcccccccccc} 
Physical Attractiveness & 1 & $3.0(1.0)$ & $3.5(1.3)$ & $2.7(0.6)$ & $2.6(0.8)$ & $2.9(1.2)$ & $2.5(0.5)$ & $2.4(1.0)$ & $2.8(1.1)$ & $2.2(1.0)$ \\
& 2 & $2.6(1.0)$ & $3.0(1.0)$ & $2.3(0.9)$ & $2.9(0.7)$ & $3.3(0.8)$ & $2.7(0.6)$ & $2.8(1.1)$ & $3.4(1.0)$ & $2.5(1.0)$ \\
& 3 & $2.9(0.7)$ & $3.2(0.6)$ & $2.7(0.7)$ & $2.9(0.6)$ & $3.1(0.4)$ & $2.8(0.7)$ & $2.8(0.5)$ & $2.8(0.4)$ & $2.7(0.6)$ \\
& 4 & $2.9(0.7)$ & $3.1(0.5)$ & $2.8(0.8)$ & $3.2(0.8)$ & $3.6(0.6)$ & $2.9(0.8)$ & $2.9(0.9)$ & $3.1(0.9)$ & $2.8(0.9)$ \\
Sport Competence & 5 & $2.7(1.1)$ & $3.3(1.0)$ & $2.3(1.1)$ & $3.0(0.9)$ & $3.6(0.8)$ & $2.7(0.7)$ & $2.9(0.8)$ & $3.2(0.8)$ & $2.8(0.8)$ \\
& $M$ & $2.8(0.9)$ & $3.2(0.9)$ & $2.4(0.7)$ & $2.9(0.8)$ & $3.3(0.8)$ & $2.6(0.6)$ & $2.8(0.9)$ & $3.0(0.9)$ & $2.5(0.7)$ \\
& 1 & $2.7(0.9)$ & $2.9(1.1)$ & $2.5(0.7)$ & $3.0(1.3)$ & $3.6(1.6)$ & $2.7(1.0)$ & $3.0(0.9)$ & $3.3(1.1)$ & $2.8(0.8)$ \\
& 2 & $3.0(0.9)$ & $3.2(0.8)$ & $2.8(1.0)$ & $2.5(1.0)$ & $2.6(1.0)$ & $2.3(1.0)$ & $2.4(0.8)$ & $2.7(0.8)$ & $2.2(0.8)$ \\
& 3 & $3.0(0.9)$ & $3.0(1.0)$ & $2.9(0.8)$ & $3.0(1.0)$ & $3.2(0.8)$ & $2.9(1.1)$ & $3.2(0.7)$ & $3.1(0.5)$ & $3.2(0.8)$ \\
& 4 & $3.0(0.9)$ & $2.8(1.0)$ & $3.1(0.9)$ & $2.7(1.1)$ & $3.1(1.1)$ & $2.5(1.0)$ & $3.3(0.8)$ & $2.5(0.5)$ & $3.1(0.9)$ \\
& 5 & $3.3(0.8)$ & $3.6(0.6)$ & $3.1(0.9)$ & $3.2(1.0)$ & $3.4(1.0)$ & $3.0(1.0)$ & $3.3(1.1)$ & $3.5(0.9)$ & $3.2(1.2)$ \\
& $M$ & $3.0(0.9)$ & $3.1(0.9)$ & $2.9(0.9)$ & $2.9(1.1)$ & $3.2(1.1)$ & $2.7(1.0)$ & $3.0(0.9)$ & $3.2(0.8)$ & $2.9(1.0)$ \\
\hline
\end{tabular}

Note. VIT $=$ vigorous interval training. 
Table 4

Results of the Analysis of Covariance for Physical Self-Perceptions According to the Type of VIT, Time, Sex, and Their Interactions While Controlling for Weight Loss

\begin{tabular}{|c|c|c|c|c|c|c|c|c|c|c|c|c|c|c|c|c|}
\hline \multirow[b]{2}{*}{ Scales } & \multicolumn{2}{|c|}{$\begin{array}{c}\text { Covariate } \\
\text { weight loss }\end{array}$} & \multicolumn{2}{|c|}{ VIT } & \multicolumn{2}{|c|}{ Sex } & \multicolumn{2}{|c|}{ Time } & \multicolumn{2}{|c|}{ VIT $\times$ Sex } & \multicolumn{2}{|c|}{ VIT $\times$ Time } & \multicolumn{2}{|c|}{ Sex $\times$ Time } & \multicolumn{2}{|c|}{ VIT $\times$ Sex $\times$ Time } \\
\hline & $F(1,65)$ & $p$ & $F(2,65)$ & $p$ & $F(1,65)$ & $p$ & $F(4,260)$ & $p$ & $F(2,65)$ & $p$ & $F(8,260)$ & $p$ & $F(4,260)$ & $p$ & $F(8,260)$ & $p$ \\
\hline Global Self-Worth & 0.22 & .64 & 0.18 & .84 & 15.42 & $<.001$ & 2.44 & .048 & 0.11 & .89 & 2.49 & .013 & 1.73 & .14 & 1.26 & .26 \\
\hline $\begin{array}{l}\text { Physical } \\
\text { Self-Worth }\end{array}$ & 0.26 & .62 & 0.33 & .72 & 7.06 & .01 & 3.95 & .004 & 0.45 & .64 & 1.71 & .96 & 2.35 & .06 & 0.61 & .77 \\
\hline Physical Strength & 0.37 & .54 & 0.56 & .58 & 17.64 & $<.001$ & 6.0 & $<.001$ & 0.43 & .65 & 2.70 & .007 & 3.05 & .02 & 1.32 & .24 \\
\hline $\begin{array}{l}\text { Physical } \\
\text { Condition }\end{array}$ & 0.12 & .73 & 0.69 & .51 & 9.50 & .003 & 4.39 & .002 & 0.54 & .58 & 4.17 & $<.001$ & 1.06 & .38 & 0.99 & .45 \\
\hline $\begin{array}{l}\text { Physical } \\
\text { Attractiveness }\end{array}$ & 0.47 & .50 & 0.51 & .60 & 14.15 & $<.001$ & 1.30 & .27 & 0.16 & .85 & 2.65 & .008 & 1.39 & .24 & 0.77 & .63 \\
\hline Sport Competence & 0.01 & .32 & 0.14 & .87 & 2.90 & .09 & 10.46 & $<.001$ & 0.18 & .83 & 3.53 & $<.001$ & 2.63 & .04 & 0.85 & .56 \\
\hline
\end{tabular}

Note. $\mathrm{VIT}=$ vigorous interval training. Bold indicates the significant values. 
A
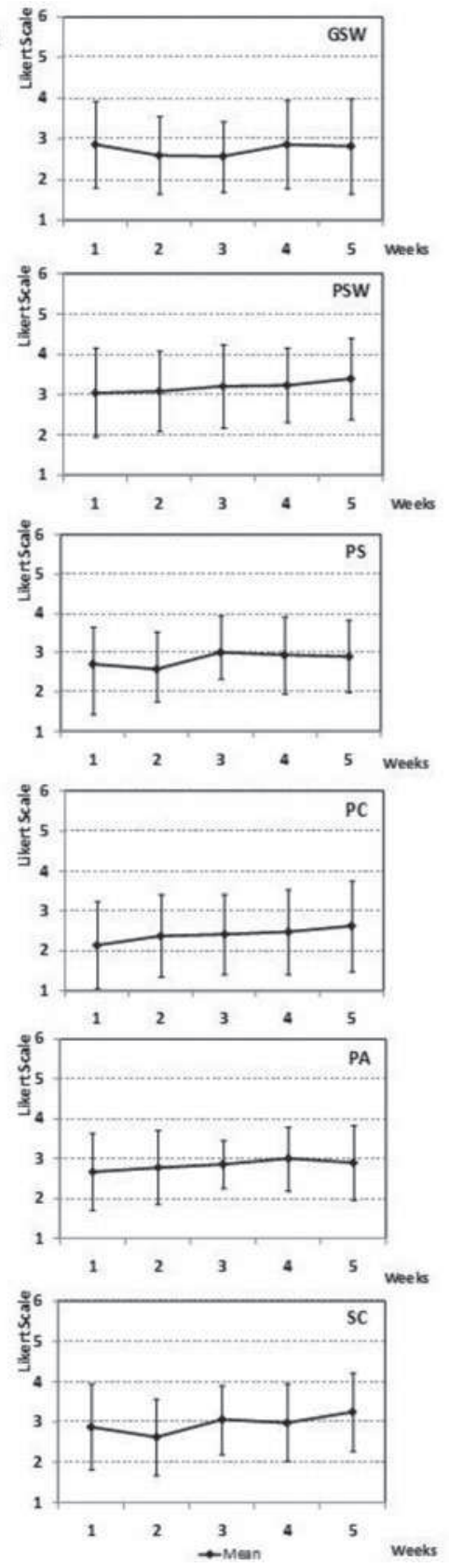

B
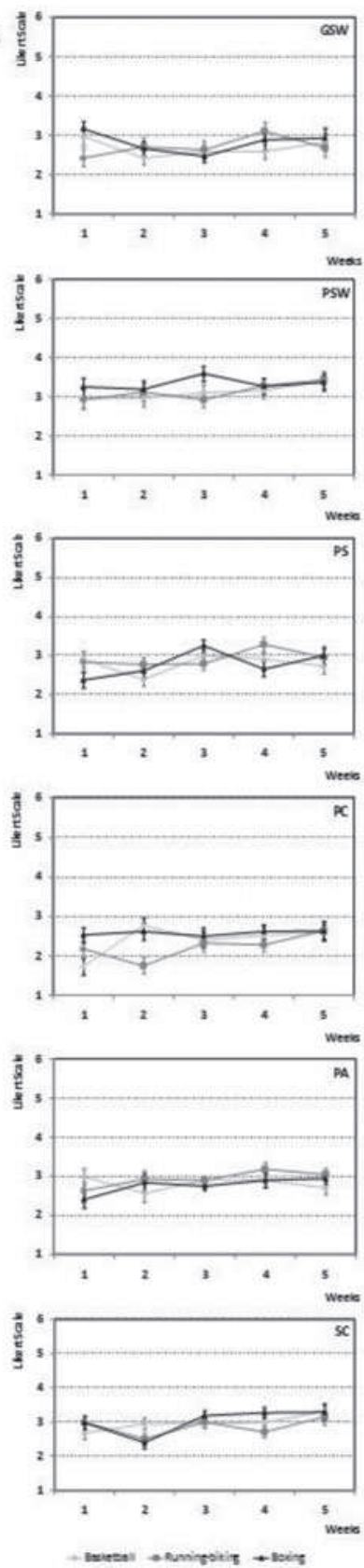

Figure 1. (A) Effects of time for each physical self-perception. (B) Effects of type of vigorous interval training (i.e., basketball, running-biking, or boxing) by time for each physical self-perception. Note. GSW = global self-worth; PSW = physical self-worth; PS = physical strength; $\mathrm{PC}=$ physical condition; $\mathrm{PA}=$ physical attractiveness; $\mathrm{SC}=$ sport competence. 
$-0.42)$ and subsequently increased between S2 and S3 $(p=.047, d=0.50)$ and $\mathrm{S} 2$ and $\mathrm{S} 5$ $(p=.002, d=0.66)$ for the running-biking VIT, and (c) decreased between $\mathrm{S} 1$ and $\mathrm{S} 2(p=$ $.007, d=-0.65)$ and increased between $\mathrm{S} 2$ and $\mathrm{S} 3(p<.001, d=1.01), \mathrm{S} 2$ and $\mathrm{S} 4(p<.001$, $d=1.05)$, and S2 and S5 $(p<.001, d=0.90)$ for the boxing VIT. In addition, a significant Sex $\times$ Time effect indicated increased scores: (a) for boys, between S2 and S5 ( $p<.001, d=$ $0.74), \mathrm{S} 3$ and $\mathrm{S} 5(p=.017, d=0.49)$, and S4 and S5 ( $p=.016, d=0.43)$, and (b) for girls, between S1 and S3 $(p=.033, d=0.42), \mathrm{S} 1$ and $\mathrm{S} 5(p=.008, d=0.48), \mathrm{S} 2$ and $\mathrm{S} 3(p<$ $.001, d=0.59)$, S2 and S4 $(p=.006, d=0.45)$, and S2 and S5 $(p<.001, d=0.64)$. Finally, the significant main effect of time showed that scores decreased between S1 and S2 $(p=.004$, $d=-0.26)$ and increased between $\mathrm{S} 2$ and $\mathrm{S} 3(p<.001, d=0.48), \mathrm{S} 2$ and $\mathrm{S} 4(p<.001, d=$ $0.39), \mathrm{S} 1$ and $\mathrm{S} 5(p<.001, d=0.36), \mathrm{S} 2$ and $\mathrm{S} 5(p<.001, d=0.66), \mathrm{S} 3$ and $\mathrm{S} 5(p=.030$, $d=0.22)$, and $\mathrm{S} 4$ and $\mathrm{S} 5(p=.012, d=0.27)$.

\section{DISCUSSION}

The main objective of this study was to examine the repeated effects of VIT sessions in basketball, running-biking, and boxing on the physical self-perceptions of obese adolescents. Because all the adolescents also followed a specific diet, their weight loss over the 5 weeks of the study was controlled for.

The findings revealed that despite short-term BMI and BF changes being observed (Cole, Faith, Pietrobelli, \& Heo, 2005), this effect did not have any significant influence on the obese adolescents' physical self-perceptions. The findings revealed also that the exercise intensity was vigorous and stable during the repeated exercise sessions and did not differ significantly among sessions. Moreover, the types of exercises defined by their effort and recovery phases induced many significantly different physiological stress levels but elicited $\mathrm{HR}_{\text {peak }}$ systematically over $80 \%$ of $\mathrm{HR}_{\max }$. As expected, the $\mathrm{HR}_{\text {mean }}$ values of the three VIT sessions, which included the warm-up, cooldown, and intermediate recovery phases, were much lower (varying from 119 to 134 beats per minute). Moreover, these values differed because of the difference in design of each VIT session.

The findings for the effect of time showed that repeated VIT sessions have a significant effect on obese adolescents' physical self-perceptions (except for global self-worth and physical attractiveness). More specifically, the results showed a rapid and constant increase in physical self-worth, physical strength, and physical condition from the 2 nd to the 5th week. It can be hypothesized that these effects were rapid and constant because they were directly connected to the adolescent's physical involvement and that the physical strength and physical condition were the ones solicited by the three sport activities. In line with the hierarchical Exercise Self-Esteem Model (EXSEM) by Sonstroem and Morgan (1989), these findings show that the adolescents may have experienced several successive positive accomplishments in physical strength and physical condition and that this may have led them to perceive their physical abilities more positively. Given that the adolescents reported on their perceived PSP immediately after each session based on the current training session, their answers may have been influenced mostly by their psychological state, itself influenced by the type of VIT session. Therefore, based on the EXSEM, it appears that the improvement of actual physical abilities due to physical training may positively generalize to specific PSP (Sonstroem, Harlow, \& Josephs, 1994). Also, specific physical self-perceptions may in turn induce positive changes in more general physical (physical self-worth) or global (global self-worth) self-perceptions.

In addition, the results also showed that VIT sessions create a slight simultaneous decrease in perceived sport competence during the first 2 weeks, followed by a constant increase until 
the end. The obese adolescents may have had to master numerous (and maybe new) skills in the various types of sport activities (dribbling and passing in basketball; punching and kicking in boxing, etc.). It is thus probable that the adolescents were unbalanced in this situation and therefore perceived themselves as less competent in sports and less satisfied with themselves in general. Using the expanded EXSEM, Megakli, Vlachopoulos, Thøgersen-Ntoumani, and Theodorakis (2017) showed that self-efficacy had significant effects over time on all subdomains of PSP in middle-age women. Consequently, in the present study, the increase in perceived sport competence during the last 3 weeks may be attributed to the fact that these skills were better mastered.

Subsequent results showed that obese male adolescents have significantly higher global self-worth and PSP (except for sport competence) than obese female adolescents. These results are consistent with previous findings (e.g., Hau et al., 2005; Marsh et al., 2007; Sung et al., 2005). In addition, the results also showed a significant increase in the boys' and girls' sport competence during the 5 weeks. Surprisingly, however, no sex-based difference was observed in the effects of VIT on PSP. Consequently, although boys had higher physical PSP than girls at baseline, the effects of the VIT sessions in basketball, running-biking, or boxing were of similar magnitude. These findings thus revealed that sex-based differences in physical self-perceptions were not increased by these types of VIT. Consequently, they can be used confidently among mixed-sex samples.

Finally, the findings show that the VIT sessions in basketball and running-biking represent effective means for improving perceived physical condition and sport competence. However, these effects were rapid and constant in basketball, whereas they intervened after a slight decrease during the first 2 weeks in running-biking. This difference can be explained by the fact that in the basketball VIT sessions, the adolescents spent a longer time on the court, which may have led them to continuously perceive their physical condition and sport competence more positively. Moreover, in the running-biking VIT, the first two sessions may have been uncomfortable and unpleasant because of the duration of vigorous intensity (Ekkekakis, Parfitt, \& Petruzzello, 2011). These negative feelings may have thus led these adolescents to perceive themselves as less competent in terms of physical condition in running-biking. So, as highlighted by Jung et al. (2014), for high-intensity interval training, VIT can be considered to promote actual physical abilities through exercise. Meanwhile, the effects of boxing VIT on physical self-perceptions were mixed and inconsistent. Indeed, although perceived physical strength increased significantly, global self-worth and sport competence first decreased significantly and then increased significantly. These findings may have been influenced by the too-short time spent working out, which may not have left obese adolescents sufficient time to perceive their physical fitness and performance positively. In addition, it is possible that the skills practiced in the intermittent noncontact boxing were more complex, thus requiring more time to appropriate than in the other VIT exercises. Consequently, it appears that the adolescents encountered more difficulties during the boxing VIT and that this had a greater effect on of their perceived physical abilities.

Overall, the VIT model presented can be considered effective training for entering obese adolescents in a virtuous circle. Therefore, VIT is ergonomic because of its structure, its repetitive effective work bouts, and its overall duration. Moreover, integrating sport activities in the VIT sessions arouses curiosity through an original way of exercising and through feedback from the monitoring equipment. The observations made during the program showed that the participants were interested and probably motivated by their HR results.

In conclusion, this study shows that VIT represents an effective means of enhancing obese adolescents' global self-worth and physical self-perceptions (all scales of PSP except physical self-worth) over time. More specifically, it highlights that the effect of VIT may be rapid 
and constant and that the basketball type of VIT may be the most appropriate for improving perceived physical condition and sport competence. On one hand, VIT involves participants in a self-realization through unusual high performance and higher physical activity levels than their usual activities. On the other hand, the use of sport activity encourages them to become active because of the pleasure experienced. This study defined a VIT model that is an alternative to various types of exercises, including high-intensity interval training targeted at several intensities and different durations with usual locomotion, such as cycling or running (e.g., Jung et al., 2014). The singularity of the VIT here is to integrate different sport activities at the same intensity to improve physical self-perceptions of obese adolescents. By improving their physical self-perceptions, the participants could be more motivated to become involved in physical activities, which in turn could increase their body satisfaction.

However, these results should be interpreted with caution due to several limitations. First, this study was conducted among a limited sample of obese adolescents, and this may have limited the power of the analyses. Second, this study did not include a group of obese adolescents involved in aerobic or resistance exercises; consequently, it is unknown whether VIT may be more efficient than other types of exercise for improving obese adolescents' PSP. Third, the VIT was coupled with specific sport activities, that is, basketball, running-biking, and boxing. Therefore, the adolescents' PSP may have been influenced by these specific sports activities. It is thus unknown whether similar results can be obtained with other sport activities. Fourth, the adolescents' actual physical abilities or skills solicited in the various sport activities (e.g., dribbling, running and biking, kicking) proposed were not measured. Consequently, it is unknown whether the adolescents' changes in the sport skills or abilities may have influenced their PSP. Fifth, given that the wording of the PSI-VS items was not specific to each sport activity, it cannot be excluded that the changes in PSP may result from a delayed effect or a cumulative effect, rather than from the effect of specific sport activity. Finally, although the peak values measured in the various sessions revealed an appropriate description of the actual effort, the lack of distinct measurements for the workouts and rest periods precludes us from establishing a link from their respective changes in HR and energy expenditure mean values to those of the participants' PSP for each different sport activity.

In sum, this physical activity program could be relevant in a clinical obesity treatment. Indeed, the length of the workout or rest may play a role in the pleasure and tolerance as a dose effect. Although exercise intensity is often associated with such affective responses as displeasure, because of fatigue or anxiety, it could also yield some positive changes, such as improvement of self-esteem (Ekkekakis et al., 2011). Stronger, unusual, and unexpected sensations due to enhanced physical prowess or performance (perceived or real) could be related to the improvement of PSP. However, these repercussions are variable. Consequently, the effects of various intensities should be examined more closely in the future.

\section{ACKNOWLEDGMENTS}

We thank the pediatric rehabilitation center, the staff and the youth of $\mathrm{AJO}^{\circledR}$ Les Oiseaux, Pediatric Obesity Follow-up and Rehabilitation Care of "Le Noble Age" group for their support and participation in this study.

\section{ORCID}

Caroline Nicol http://orcid.org/0000-0002-5871-2284 


\section{REFERENCES}

Alahmadi, M. A. (2014). High-intensity interval training and obesity. Journal of Novel Physiotherapies, 4(3), 211. doi:10.4172/2165-7025.1000211

Babic, M. J., Morgan, P. J., Plotnikoff, R. C., Lonsdale, C., White, R. L., \& Lubans, D. R. (2014). Physical activity and physical self-concept in youth: Systematic review and meta-analysis. Sports Medicine, 44(11), 1589-1601. doi:10.1007/s40279-014-0229-z

Bartlett, J. D., Close, G. L., MacLaren, D. P. M., Gregson, W., Drust, B., \& Morton, J. P. (2011). High-intensity interval running is perceived to be more enjoyable than moderate-intensity continuous exercise: Implications for exercise adherence. Journal of Sports Sciences, 29, 547-553. doi:10.1080/02640414.2010.545427

Berger, B. G. (2004). Subjective well-being in obese individuals: The multiple roles of exercise. Quest, 56(1), 50-76. doi:10.1080/00336297.2004.10491815

Cohen, J. (1988). Statistical power analysis for the behavioral sciences (2nd ed., p. 567). Hillsdale, NJ: Erlbaum.

Cole, T. J., Bellizzi, M. C., Flegal, K. M., \& Dietz, W. H. (2000). Establishing a standard definition for child overweight and obesity worldwide: International survey. British Medical Journal, 320(7244), 1240-1243. doi:10.1136/bmj.320.7244.1240

Cole, T. J., Faith, M. S., Pietrobelli, A., \& Heo, M. (2005). What is the best measure of adiposity change in growing children: BMI, BMI\%, BMI z-score or BMI centile? European Journal of Clinical Nutrition, 59(3), 419-425. doi:10.1038/sj.ejcn.1602090

Costigan, S. A., Eather, N., Plotnikoff, R. C., Taaffe, D. R., \& Lubans, D. R. (2015). High-intensity interval training for improving health-related fitness in adolescents: A systematic review and meta-analysis. British Journal of Sports Medicine, 49(19), 1253-1261. doi:10.1136/bjsports-2014094490

Daley, A. J., Copeland, R. J., Wright, N. P., Roalfe, A., \& Wales, J. K. (2006). Exercise therapy as a treatment for psychopathologic conditions in obese and morbidly obese adolescents: A randomized, controlled trial. Pediatrics, 118(5), 2126-2134. doi:10.1542/peds.2006-1285

Donnelly, J. E., Blair, S. N., Jakicic, J. M., Manore, M. M., Rankin, J. W., \& Smith, B. K. (2009). American college of sports medicine position stand. Appropriate physical activity intervention strategies for weight loss and prevention of weight regain for adults. Medicine and Science in Sports and Exercise, 41(2), 459-471. doi:10.1249/MSS.0b013e3181949333

Durnin, J. V. G. A., \& Womersley, J. V. G. A. (1974). Body fat assessed from total body density and its estimation from skinfold thickness: Measurements on 481 men and women aged from 16 to 72 years. British Journal of Nutrition, 32(01), 77-97. doi:10.1079/BJN19740060

Ekkekakis, P., Parfitt, G., \& Petruzzello, S. J. (2011). The pleasure and displeasure people feel when they exercise at different intensities. Sports Medicine, 41(8), 641-671. doi:10.2165/11590680000000000-00000

Ekkekakis, P., \& Petruzzello, S. J. (1999). Acute aerobic exercise and affect. Sports Medicine, 28(5), 337-347. doi:10.2165/00007256-199928050-00005

Ekkekakis, P., Vazou, S., Bixby, W. R., \& Georgiadis, E. (2016). The mysterious case of the public health guideline that is (almost) entirely ignored: Call for a research agenda on the causes of the extreme avoidance of physical activity in obesity. Obesity Reviews, 17, 313-329. doi: 10.1111/obr.12369

Epstein, L. H., \& Goldfield, G. S. (1999). Physical activity in the treatment of childhood overweight and obesity: Current evidence and research issues. Medicine and Science in Sports and Exercise, 31(11, Suppl.), S553-559. doi:10.1097/00005768-199911001-00011

Farah, B. Q., Ritti-Dias, R. M., Balagopal, P., Hill, J. O., \& Prado, W. L. (2014). Does exercise intensity affect blood pressure and heart rate in obese adolescents? A 6-month multidisciplinary randomized intervention study. Pediatric Obesity, 9(2), 111-120. doi:10.1111/j.2047-6310.2012.00145.x

Fox, K. R., \& Corbin, C. B. (1989). The physical self-perception profile: Development and preliminary validation. Journal of Sport \& Exercise Psychology, 11(4), 408-430. doi:10.1123/jsep.11.4.408

García-Hermoso, A., Cerrillo-Urbina, A. J., Herrera-Valenzuela, T., Cristi-Montero, C., Saavedra, J. M., \& Martínez-Vizcaíno, V. (2016). Is high-intensity interval training more effective on improving 
cardiometabolic risk and aerobic capacity than other forms of exercise in overweight and obese youth? A meta-analysis. Obesity Reviews, 17, 531-540. doi:10.1111/obr.12395

Gibala, M. J., Little, J. P., MacDonald, M. J., \& Hawley, J. A. (2012). Physiological adaptations to lowvolume, high-intensity interval training in health and disease. The Journal of Physiology, 590(5), 1077-1084. doi:10.1113/jphysiol.2011.224725

Goldfield, G. S., Kenny, G. P., Alberga, A. S., Prud'homme, D., Hadjiyannakis, S., Gougeon, R., \& Wells, G. A. (2015). Effects of aerobic training, resistance training, or both on psychological health in adolescents with obesity: The HEARTY randomized controlled trial. Journal of Consulting and Clinical Psychology, 83(6), 1123-1135. doi:10.1037/ccp0000038

Harter, S. (1985). Competence as a dimension of self-evaluation: Toward a comprehensive model of self-worth. The Development of the Self, 2, 55-121.

Harter, S. (1995). Manual for the self-perception profile for adolescents. Denver, CO: University of Denver.

Hau, K. T., Sung, R. Y. T., Yu, C. W., Marsh, H. W., \& Lau, P. W. C. (2005). Factorial structure and comparison between obese and non-obese Chinese children's physical self-concept. In H. W. Marsh, R. Craven, \& D. M. McInerney (Eds.), The new frontiers of self-research (pp. 259-272). Charlotte, NC: Information Age.

Howley, E. T. (2001). Type of activity: Resistance, aerobic and leisure versus occupational physical activity. Medicine and Science in Sports and Exercise, 33(6, Suppl.), S364-S369. doi:10.1097/00005768-200106001-00005

Jakicic, J. M., Marcus, B. H., Gallagher, K. I., Napolitano, M., \& Lang, W. (2003). Effect of exercise duration and intensity on weight loss in overweight, sedentary women: A randomized trial. Journal of the American Medical Association, 290(10), 1323-1330. doi:10.1001/jama.290.10.1323

Jung, M. E., Bourne, J. E., \& Little, J. P. (2014). Where does HIT fit? An examination of the affective response to high-intensity intervals in comparison to continuous moderate-and continuous vigorous-intensity exercise in the exercise intensity-affect continuum. PloS One, 9(12), e114541. doi:10.1371/journal.pone. 0114541

Logan, G. R., Harris, N., Duncan, S., \& Schofield, G. (2014). A review of adolescent high-intensity interval training. Sports Medicine, 44(8), 1071-1085. doi:10.1007/s40279-014-0187-5

Maïano, C., Morin, A. J., Ninot, G., Monthuy-Blanc, J., Stephan, Y., Florent, J. F., \& Vallée, P. (2008). A short and very short form of the physical self-inventory for adolescents: Development and factor validity. Psychology of Sport and Exercise, 9(6), 830-847. doi:10.1016/j.psychsport.2007.10.003

Maïano, C., Ninot, G., \& Bilard, J. (2004). Age and gender effects on global self-esteem and physical self-perception in adolescents. European Physical Education Review, 10(1), 53-69. doi:10.1177/1356336x04040621

Marsh, H. W. (1998). Age and gender effects in physical self-concepts for adolescent elite athletes and non athletes: A multicohort-multioccasion design. Journal of Sport and Exercise Psychology, 20, 237-259.

Marsh, H. W., Hau, K. T., Sung, R. Y., \& Yu, C. W. (2007). Childhood obesity, gender, actual-ideal body image discrepancies, and physical self-concept in Hong Kong children: Cultural differences in the value of moderation. Developmental Psychology, 43(3), 647-662. doi:10.1037/0012-1649.43.3.647

Marsh, H. W., Richards, G. E., Johnson, S., Roche, L., \& Tremayne, P. (1994). Physical SelfDescription Questionnaire: Psychometric properties and a miiltitrait-meltimethod analysis of relations to existing instruments. Journal of Sport and Exercise Psychology, 16(3), 270-305. doi:10.1123/jsep.16.3.270

McCullough, N., Muldoon, O., \& Dempster, M. (2009). Self-perception in overweight and obese children: A cross-sectional study. Child: Care, Health and Development, 35(3), 357-364. doi:10.1111/j.1365-2214.2008.00924.x

Megakli, T., Vlachopoulos, S. P., Thøgersen-Ntoumani, C., \& Theodorakis, Y. (2017). Impact of aerobic and resistance exercise combination on physical self-perceptions and self-esteem in women with obesity with one-year follow-up. International Journal of Sport \& Exercise Psychology, 15, 236 257. doi:10.1080/1612197X.2015.1094115 
Morin, A. J., \& Maïano, C. (2011). Cross-validation of the short form of the physical self-inventory (PSI-S) using exploratory structural equation modeling (ESEM). Psychology of Sport and Exercise, 12(5), 540-554. doi:10.1016/j.psychsport.2011.04.003

Powell, S. M., \& Rowlands, A. V. (2004). Inter monitor variability of the RT3 accelerometer during typical physical activities. Medicine and Science in Sports and Exercise, 36(2), 324-330. doi:10.1249/01.MSS.0000113743.68789.36

Rey, O., Vallier, J. M., Nicol, C., Mercier, C. S., \& Maïano, C. (2017). Effects of combined vigorous interval training program and diet on body composition, Physical fitness, and physical self-perceptions among obese adolescent boys and girls. Pediatric Exercise Science, 29(1), 1-27. doi:10.1123/pes.2016-0105

Rowlands, A. V., Ingledew, D. K., Powell, S. M., \& Eston, R. G. (2004). Interactive effects of habitual physical activity and calcium intake on bone density in boys and girls. Journal of Applied Physiology, 97(4), 1203-1208. doi:10.1152/japplphysiol.00182.2004

Siri, W. E. (1961). Body composition from fluid spaces and density: Analysis of methods. Techniques for Measuring Body Composition, 61, 223-244.

Sonstroem, R. J., Harlow, L. L., \& Josephs, L. (1994). Exercise and self-esteem: Validity of model expansion and exercise associations. Journal of Sport \& Exercise Psychology, 16, 29-42. doi:10.1123/jsep.16.1.29

Sonstroem, R. J., \& Morgan, W. P. (1989). Exercise and self-esteem: Rationale and model. Medicine \& Science in Sports \& Exercise, 21, 329-337. doi:10.1249/00005768-198906000-00018

Sung, R. Y. T., Yu, C. W., So, R. C. H., Lam, P. K. W., \& Hau, K. T. (2005). Self-perception of physical competences in preadolescent overweight Chinese children. European Journal of Clinical Nutrition, 59, 101-106. doi:10.1038/sj.ejcn.1602044

Tan, S., Yang, C., \& Wang, J. (2010). Physical training of 9-10 year old children with obesity to lactate threshold intensity. Pediatric Exercise Science, 22(3), 477-485. doi:10.1123/pes.22.3.477

Tanaka, H., Monahan, K. D., \& Seals, D. R. (2001). Age-predicted maximal heart rate revisited. Journal of the American College of Cardiology, 37(1), 153-156. doi:10.1016/S0735-1097(00)01054-8

Tarp, J., Andersen, L. B., \& Østergaard, L. (2015). Quantification of underestimation of physical activity during cycling to school when using accelerometry. Journal of Physical Activity \& Health, 12, 701707. doi:10.1123/jpah.2013-0212

Westerterp, K. R. (1999). Physical activity assessment with accelerometers. International Journal of Obesity \& Related Metabolic Disorders, 23(3, Suppl.), S45-S49. doi:10.1038/sj.ijo.0800883

Whitehead, J. R. (1995). A study of children's physical self-perceptions using an adapted physical selfperception profile questionnaire. Pediatric Exercise Science, 7, 132-151. doi:10.1123/pes.7.2.132

Yu, C. C. W., Sung, R. Y. T., Hau, K. T., Lam, P. K. W., Nelson, E. A. S., \& So, R. C. H. (2008). The effect of diet and strength training on obese children's physical self-concept. Journal of Sports Medicine and Physical Fitness, 48(1), 76-82. 